\title{
Inter-limb blood pressure difference, ankle-brachial index and its association with border zone cerebral infarcts: A prospective single-blind study from central India
}

Sodani Ajoy ${ }^{1}$, Rathi Pankaj ${ }^{1}$, Jain Rahul ${ }^{1,{ }^{*}}$, Chouksey Dinesh ${ }^{1}$, Telang Kapi ${ }^{1}$ and Bhagat Manish ${ }^{2}$

${ }^{1}$ Department of Neurology, Sri Aurobindo Institute of Medical Sciences, Indore, Madhya Pradesh, India

${ }^{2}$ Department of Radiology, Sri Aurobindo Institute of Medical Sciences, Indore, Madhya Pradesh, India

\begin{abstract}
Background: Border zone infarcts (BZI) are ischemic lesions occurring between two non- anastomosing arterial territories. BZI patients have higher incidence of recurrent strokes (RS). The predictors of peripheral arterial disease (PAD), low ankle-brachial index (ABI) and high inter-arm blood pressure difference (IABD) are associated with intracranial atherosclerosis and thus, could also have an association with BZI. Our single blind prospective study explores the predictive value of these clinical variables, ABI and IABD for BZI in patients with acute ischemic stroke.
\end{abstract}

Methods: The subjects fulfilling the inclusion criterion (183 of 335, 78.14\% men) were divided into BZI ( $\mathrm{n}=89$ ) and pure core arterial territory infarct (CATI, $n=94$ ) groups, based upon MRI characteristics of infarcts. The value of ABI $(<1$ or $\geq 1)$ and IABD $(<10$ or $\geq 10 \mathrm{mmHg}$ ) was deduced in all the subjects. The groups were compared using the clinical features, $\mathrm{ABI}$ and IABD values as variables.

Results: Odds for BZI were high in men (OR 1.78, 95\% CI 0.87-3.66), hypertension ( $\mathrm{p}=0.003$, OR 2.79, 95\% CI 1.39 to 5.6 ), history of ischemic heart disease (OR 2.06, 95\%CI 0.73-5.8), prior stroke (OR 1.92, 95\% CI 0.54-6.8), smoking (OR1.85, 95\% CI 0.96-3.56) and dyslipidemia (OR2.5, 95\% CI 0.83-7.58). ABI mean (ABI-M) <1 was significantly associated with BZI $(\mathrm{p}=0.022)$ as compared to CATI. ABI-M of $<0.96$ was able to diagnose BZI over CATI (sensitivity $56.2 \%$, specificity $63.8 \%$, p $<0.05$ ).IABD $\geq 10 \mathrm{~mm}$ Hg showed no association with BZI. Logistic regression analysis showed that HTN $(\mathrm{p}<0.001)$ and low ABI-M $(\mathrm{p}<0.033)$ were a significant predictor of BZI.

Conclusion: Low ABI-M could be of value as a screening tool to identify persons at risk for BZI in stroke population.

Keywords: Border-zone infarct; ankle-brachial index; inter-arm blood pressure difference; stroke; intracranial arterial stenosis; peripheral arterial disease; hypertension

\begin{abstract}
*Corresponding author: Dr. Rahul Jain, Sri Aurobindo Institute of Medical Sciences, Indore, India. Mobile: 7415511663; Email: drrahulneuro@gmail.com
\end{abstract}

Received 17 January 2020; Revised 3 March 2020; Accepted 14 March 2020; Published 28 March 2020

Citation: Ajoy S, Pankaj R, Rahul J, Dinesh C, Kapil T, Manish B. Inter-limb blood pressure difference, ankle-brachial index and its association with border zone cerebral infarcts: A prospective single-blind study from central India. J Med Sci Res. 2020; 8(2):5765. DOI: http://dx.doi.org/10.17727/JMSR.2020/8-8

Copyright: (C) 2020 Ajoy S et al. Published by KIMS Foundation and Research Center. This is an open-access article distributed under the terms of the Creative Commons Attribution License, which permits unrestricted use, distribution, and reproduction in any medium, provided the original author and source are credited. 


\section{Introduction}

Stroke is potentially preventable yet a devastating cause of mortality and morbidity worldwide [1]. Despite big advancements in the secondary prophylaxis strategies the ischemic strokes continue to recur (RS), at times with alarmingly high rate [2]. Furthermore, some ethnic groups seem to be at higher risk for RS. Recently, a group of Chinese researchers has cited a threefold increased incidence of RS between 2006 and 2012 [3].

Three patterns of ischemic infarcts have been described: (a) confined to the perforator territory; (b) lying within the core vascular territory of a major intracranial artery (CATI) and (c) located at the distal part of two non-anastomosing arterial systems, the border-zone infarcts (BZI) [4]. Later are further divided into internal BZI (IBZ) and external BZI (EBZ). Of these two the former is located between the deep and superficial arterial system of anterior circulation and the later between the cortical territories of the three major vessels, viz. middle (MCA), anterior (ACA) and posterior cerebral (PCA) arteries [5].

It is noteworthy that preventive strategies often yield poor results in BZI patients. Despite aggressive medical management, compared to CATI persons with BZI continue to have a higher risk of RS ( $8 \%$ vs. $26 \%$ ) [2]. Therefore, extensive research has been done to understand the mechanisms of BZI stroke [6]. It is known that the BZI differs from CATI not only in the etiopathogenesis but also in their course and prognosis [7]. In experimental studies systemic hypotension has produced BZI [8]. BZI has been linked with clinical situations leading to systemic hypotension, including iatrogenic [9]. Recent research has linked BZI with hypo-perfusion due to higher degree of intracranial arterial stenosis $[2,10$, 11]. It has been suggested to study the hemodynamics of the cerebral blood flow before individualizing the therapy for RS prevention [2].

In countries like India, where high-tech medical care is not accessible to a significant proportion of the population, there is an urgent need to find some easy way of identifying those at risk of RS. Recording blood pressure in all four limbs and observing the inter-arm blood pressure difference (IABD) and ankle-brachial index (ABI) is an inexpensive screening test for PAD $[12,13]$.
The association of IABD of $\geq 10 \mathrm{mmHg}$ and $\mathrm{ABI}$ of $<1$ or $\leq 0.9$ with intracranial atherosclerosis and RS and/ or stroke is already known [13-15]. Although the relationship of $\mathrm{ABI}$ and IABD with ischemic stroke is well established, to the best of our knowledge their association with BZI alone is not known.

We, therefore, set to study the association of $\mathrm{ABI}$ and IABD with BZI in the subjects with acute ischemic stroke. We also planned to look into the clinical and demographic factors associated with BZI.

\section{Material, methods and data management}

The study was conducted in the neurology department of a medical college hospital. After obtaining informed consent, we prospectively enrolled patients aged $>18$ years admitted with acute ischemic stroke $(\mathrm{n}=355,71 \%$ male) from March 2018 through July 2019. Subjects with, recent head trauma $(n=2)$, vasculopathy $(n=5)$, stroke mimic $(n=4)$ and those who could not undergo MRI of the brain $(n=141)$ were excluded (Figure 1). Remaining 183 subjects (78\% male) formed the study population. Every patient was thoroughly examined by one neurology resident (KT, PR) and a senior neurologist, later was not associated with the study.

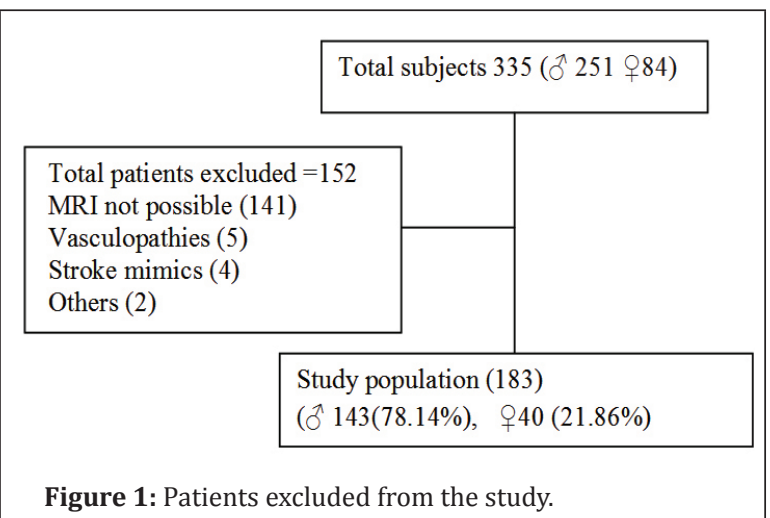

The gender and age were noted. History of prior stroke, ischemic heart disease (IHD), hypertension (HTN), diabetes (T2DM), alcohol use and smoking were sought for. Old medical records, medications were reviewed for the evidence of HTN, IHD, smoking, T2DM.

Supine four limb BP was measured in all the subjects by a trained and supervised team of nurses using an automated device (PHILIPS IntelliVue MP 20), 
according to the available guideline [15]. The upper extremity BP was recorded over the brachial artery and that in the lower extremity was measured over the posterior tibial artery at the ankle. Three readings of the systolic $\mathrm{BP}$ (SBP) and diastolic BP (DBP) were noted at each site.

$\mathrm{ABI}$, defined as the ratio of SBP measured over posterior tibial and brachial arteries, was calculated as described [17]. We thus, calculated the ABI using SBP at the ankle as numerator while the highest value of the SBP, of either arm, remained the denominator. Thereby obtaining three separate ABI values- a) ABI high $(\mathrm{ABI}-\mathrm{H})$ calculated using the highest recorded SBP b) ABI mean (ABI-M) calculated with the mean of the three SBP readings and c) ABI low (ABI-L) calculated by utilizing the lowest SBP recorded. We used the oscillometric technique for measuring the $B P$ hence ABI value of $<1$ was considered abnormal [18]. Inter-arm BP difference for systolic (IASBD) and diastolic BP (IADBD) was calculated as per Chang et al.[13]. A difference of $\geq 10 \mathrm{~mm} \mathrm{Hg}$ was taken as significant.

Complete blood and biochemical profile, electrocardiogram (EKG), lipid profile, HBA1C were done in each subject and values were recorded in the study proforma.

MRI brain was performed using a $1.5 \mathrm{~T}, 18$ channel system (Magnetom Symphony, Siemens Medical Solutions, Germany). The raw data was stored in the hospital server and was discretely retrieved later by two authors, blinded for the clinical features and $\mathrm{BP}$ recordings (AKS and RJ). The diffusion-weighted (DWI), T2 weighted and fluid-attenuated inversion recovery (FLAIR) images were studied. DWI images were correlated with the apparent diffusion coefficient (ADC) maps [19]. The CATI, IBZ, and EBZ were identified and recorded on a template as described previously [20]. Peri-ventricular confluent, white matter hypertensive (leukoaraiosis) changes and discrete, focal, small T2WI hyper-intense lesions were ignored. Any discrepancy in the observation was sorted out with the help of a neuroradiologist (MB).

Subjects were divided according to age $(<60, \geq 60$ $y$ ), gender (male/ female) and presence or absence of the above-mentioned risk factors. Persons with a history of HTN, or those with SBP $>140$, DBP $>90$ on repeated measurement and patients with $\mathrm{LVH}$ on EKG or 2D Echo were considered to be hypertensive [21]. Patients with glycosylated hemoglobin (HBA1C) level of $\geq 6.5$ were considered to have T2DM [21]. Dyslipidemia was defined as total cholesterol $\geq 220$ $\mathrm{mg} / \mathrm{dl}$ or LDL $\geq 160 \mathrm{mg} / \mathrm{dl}$ [21].

The subjects with acute or chronic EBZ and IBZ, with or without CATI, were grouped as BZI $(n=89)$.Those with pure CATI (and no acute/chronic BZI) were grouped as CATI patients $(\mathrm{n}=94)$. The groups were compared for the associated risk factors and the values of the IABD and ABI.

\section{Statistical technique}

The statistical analysis was done using software like Medcalc [22], Graphpad [23], Excel 2007 [24] and SPSS version 17.0 Trial. Results of continuous data are presented as Mean \pm Standard deviation (SD) and the results of the categorical measurements are given as a percentage (\%).

As and when required, Pearson's Chi-Square test, two-tailed Fisher exact test and comparison of proportions were deployed to know the association of various risk factors with border zone infarcts. Multivariate binary logistic regression was used to predict the border zone infarcts (dependent variable) among patients by employing selected continuous and non-continuous predictors (independent variables).

The probability value $\mathrm{p} \leq 0.05$ and $\mathrm{OR}>1$ (at $95 \%$ CI) was considered significant. The study was approved by the Institutional Scientific and Research Committee.

\section{Results}

The clinical and demographic data are presented in Table 1.

Out of 183 subjects, BZI was detected in 89 (48.63\%) while $94(51.37 \%)$ had CATI. The difference was non-significant $(\mathrm{p}=0.69)$. The values of DBP, mean age and $\mathrm{HbA1C}$ did not differ significantly between BZI and CATI groups.

As compared to the CATI group the mean SBP at right arm was significantly high in the BZI group. (138 \pm 23.34 vs. $145 \pm 23.18 \mathrm{~mm} \mathrm{Hg}, \mathrm{p}=0.04$; table- 1 , section I). 
Table 1: Demographic and clinical profile of study population $(n=183)$.

\begin{tabular}{|c|c|c|c|c|c|}
\hline \multicolumn{2}{|c|}{ Variable } & $\begin{array}{c}\text { Borderzone infarcts } \\
\text { (BZI) }\end{array}$ & $\begin{array}{c}\text { Core Arterial Territory } \\
\text { Infarcts (CATI) }\end{array}$ & $\begin{array}{c}\text { OR } \\
(95 \% \mathrm{CI})^{\wedge}\end{array}$ & $\begin{array}{l}p \text {-value } \\
\text { (LOS) }\end{array}$ \\
\hline \multicolumn{6}{|l|}{ Section-I } \\
\hline \multicolumn{2}{|l|}{ Age in yr (mean \pm SD) } & $57.02 \pm 13.15$ & $58.37 \pm 14.57$ & - & $0.51^{\mathrm{ns}, \S}$ \\
\hline \multicolumn{2}{|c|}{ SBP in $\mathrm{mmHg}($ mean \pm SD) } & $145 \pm 23.18$ & $138 \pm 23.34$ & - & $0.04^{\mathrm{s}, \S}$ \\
\hline \multicolumn{2}{|c|}{ DBP in $\mathrm{mmHg}$ (mean \pm SD) } & $83.87 \pm 12.84$ & $80.06 \pm 14.26$ & - & $0.10^{\mathrm{n}, \S}$ \\
\hline \multicolumn{2}{|l|}{ HBA1C (mean \pm SD) } & $6.85 \pm 2.24$ & $6.68 \pm 2.01$ & - & $0.58^{\mathrm{ns}, \S}$ \\
\hline \multicolumn{6}{|l|}{ Section-II } \\
\hline \multirow{2}{*}{$\begin{array}{l}\text { Gender } \\
\mathrm{n}(\%)\end{array}$} & $\begin{array}{l}\text { Male } \\
\mathrm{n}=143(100)\end{array}$ & $\begin{array}{l}74 \\
(51.74)\end{array}$ & $\begin{array}{l}69 \\
(48.26)\end{array}$ & \multirow{2}{*}{$\begin{array}{l}1.78 \\
(0.87-3.66)^{\mathrm{s}}\end{array}$} & \multirow{2}{*}{$0.15^{\mathrm{ns} *}$} \\
\hline & $\begin{array}{l}\text { Female } \\
n=40(100)\end{array}$ & $\begin{array}{l}15 \\
(37.5)\end{array}$ & $\begin{array}{l}25 \\
(62.5)\end{array}$ & & \\
\hline \multirow{2}{*}{$\begin{array}{l}\text { Age } \\
\text { n (\%) }\end{array}$} & $\begin{array}{l}\geq 60 \\
86(100)\end{array}$ & $\begin{array}{l}41 \\
(47.67)\end{array}$ & $\begin{array}{l}45 \\
(52.33)\end{array}$ & \multirow{2}{*}{$\begin{array}{l}0.93 \\
(0.52-1.66)^{\mathrm{ns}}\end{array}$} & \multirow{2}{*}{$0.88^{\mathrm{ns}} *$} \\
\hline & $\begin{array}{l}<60 \\
97(100)\end{array}$ & $\begin{array}{l}48 \\
(49.48)\end{array}$ & $\begin{array}{l}49 \\
(50.52)\end{array}$ & & \\
\hline \multirow{2}{*}{$\begin{array}{l}\text { T2DM } \\
\text { n (\%) }\end{array}$} & $\begin{array}{l}\text { Yes } \\
\mathrm{n}=78(100)\end{array}$ & $\begin{array}{l}37 \\
(47.43)\end{array}$ & $\begin{array}{l}41 \\
(52.57)\end{array}$ & \multirow{2}{*}{$\begin{array}{l}0.91 \\
(0.51-1.65)^{\mathrm{ns}}\end{array}$} & \multirow{2}{*}{$0.78^{\mathrm{ns} \pi}$} \\
\hline & $\begin{array}{l}\text { No } \\
n=105(100)\end{array}$ & $\begin{array}{l}52 \\
(49.52)\end{array}$ & $\begin{array}{l}53 \\
(50.48)\end{array}$ & & \\
\hline \multirow{2}{*}{$\begin{array}{l}\text { HTN } \\
\text { n (\%) }\end{array}$} & $\begin{array}{l}\text { Yes } \\
\mathrm{n}=134(100)\end{array}$ & $\begin{array}{l}74 \\
(55.22)\end{array}$ & $\begin{array}{l}60 \\
(44.78)\end{array}$ & \multirow{2}{*}{$\begin{array}{l}2.79 \\
(1.39-5.6)^{s}\end{array}$} & \multirow{2}{*}{$0.003^{s \pi}$} \\
\hline & $\begin{array}{l}\text { No } \\
n=49(100)\end{array}$ & $\begin{array}{l}15 \\
(30.61)\end{array}$ & $\begin{array}{l}34 \\
(69.39)\end{array}$ & & \\
\hline \multirow{2}{*}{$\begin{array}{l}\text { History of IHD } \\
\mathrm{n}(\%)\end{array}$} & $\begin{array}{l}\text { Yes } \\
\mathrm{n}=17(100)\end{array}$ & $\begin{array}{l}11 \\
(64.70)\end{array}$ & $\begin{array}{l}6 \\
(35.30)\end{array}$ & \multirow{2}{*}{$\begin{array}{l}2.06 \\
(0.73-5.8)^{\mathrm{s}}\end{array}$} & \multirow{2}{*}{$0.16^{\mathrm{ns \pi}}$} \\
\hline & $\begin{array}{l}\text { No } \\
n=166(100)\end{array}$ & $\begin{array}{l}78 \\
(46.98)\end{array}$ & $\begin{array}{l}88 \\
(53.02)\end{array}$ & & \\
\hline \multirow{2}{*}{$\begin{array}{l}\text { Prior Stroke } \\
\text { n (\%) }\end{array}$} & $\begin{array}{l}\text { Yes } \\
\mathrm{n}=11(100)\end{array}$ & $\begin{array}{l}7 \\
(63.63)\end{array}$ & $\begin{array}{l}4 \\
(36.37)\end{array}$ & \multirow{2}{*}{$\begin{array}{l}1.92 \\
(0.54-6.8)^{s}\end{array}$} & \multirow{2}{*}{$0.30^{\mathrm{ns} \pi}$} \\
\hline & $\begin{array}{l}\text { No } \\
n=172(100)\end{array}$ & $\begin{array}{l}82 \\
(47.67)\end{array}$ & $\begin{array}{l}90 \\
(52.33)\end{array}$ & & \\
\hline \multirow{2}{*}{$\begin{array}{l}\text { History of Smoking } \\
\mathrm{n}(\%)\end{array}$} & $\begin{array}{l}\text { Yes } \\
n=52(100)\end{array}$ & $\begin{array}{l}31 \\
(59.61)\end{array}$ & $\begin{array}{l}21 \\
(40.39)\end{array}$ & \multirow{2}{*}{$\begin{array}{l}1.85 \\
(0.96-3.56)^{\mathrm{s}}\end{array}$} & \multirow{2}{*}{$0.061^{\mathrm{psq}}$} \\
\hline & $\begin{array}{l}\text { No } \\
n=131(100)\end{array}$ & $\begin{array}{l}58 \\
(44.27)\end{array}$ & $\begin{array}{l}73 \\
(55.73)\end{array}$ & & \\
\hline \multirow{2}{*}{$\begin{array}{l}\text { Alcohol use } \\
\text { n (\%) }\end{array}$} & $\begin{array}{l}\text { Yes } \\
n=38(100)\end{array}$ & $\begin{array}{l}22 \\
(57.89)\end{array}$ & $16(42.11)$ & \multirow{2}{*}{$\begin{array}{l}1.60 \\
(0.77-3.29)^{\mathrm{s}}\end{array}$} & \multirow{2}{*}{$0.19^{\text {nst }}$} \\
\hline & $\begin{array}{l}\text { No } \\
n=145(100)\end{array}$ & $\begin{array}{l}67 \\
(46.20)\end{array}$ & $78(53.80)$ & & \\
\hline \multirow{2}{*}{$\begin{array}{l}\text { Dyslipidemia }^{\varphi} \\
\text { n }(\%)\end{array}$} & $\begin{array}{l}\text { Yes } \\
n=16(100)\end{array}$ & $\begin{array}{l}11 \\
(68.75)\end{array}$ & $5(31.25)$ & \multirow{2}{*}{$\begin{array}{l}2.5 \\
(0.83-7.58)^{\mathrm{s}}\end{array}$} & \multirow{2}{*}{$0.11^{\mathrm{s} *}$} \\
\hline & $\begin{array}{l}\text { No } \\
n=150(100)\end{array}$ & $\begin{array}{l}70 \\
(46.66)\end{array}$ & $\begin{array}{l}80 \\
(53.34)\end{array}$ & & \\
\hline
\end{tabular}

BZI- Border zone infarct, CATI- Core Arterial Territory infarct, ${ }^{\S}$ Comparisons of means, ${ }^{\wedge}$ calculated as per Altman, 1991, *2 tailed Fischer Exact test, "Pearson Chi-Square test, ${ }^{\Pi}$ Comparison of proportion as per Altman, 1991, $\varphi$ calculated in 166 subjects, data missing $n=17$, CI-confidence interval, OR - odds ratio, SBP-systolic blood pressure, DBP-Diastolic blood pressure, LOS-Level of significance, s-significant, ns-non significant. 
A summary of the demographic and clinical profile of the study population is given in table-1section II. We found that males have higher odds $(1.98,95 \% \mathrm{CI}$ 0.87-3.66) for having BZI, although the probability did not reach statistical significance $(p=0.15)$. Similarly, those with prior stroke and a history of IHD showed higher odds for having BZI but the difference did not reach the statistical significance.

The results suggest that HTN $(n=134)$ has a strong association with the occurrence of BZI (OR 2.79, CI 1.39-5.6; $p=0.003)$. Similarly, smokers $(n=52)$ showed a trend for higher risk for BZI (OR 1.85, CI 0.96-3.56; $\mathrm{p}=0.06$ ).

The data of the lipid profile of 17 patients were missing. Results were thus calculated for the remaining 166 subjects, which depicts higher odds for BZI in patients with dyslipidemia $(\mathrm{n}=16$; OR 2.5 , CI 0.83-7.58). Odds for BZI occurrence were slightly increased (OR 1.6, CI 0.77-3.29) in those who consumed excess alcohol $(n=38)$.

We did not find any association of IASBD (OR 0.53 CI 0.27-1.03, $\mathrm{p}=0.06$ ) and IADBD (OR 0.96 CI 0.49$1.86, \mathrm{p}=0.89$ ) with BZI. The relationship of ABI with stroke pattern is given in the Table 2 .

An abnormal $A B I(<1)$ for three different techniques of calculation, ABI-H, ABI-M, and ABI-L, was found in $50.2,64.48$ and $80.87 \%$ respectively. Out of them, no association of BZI with ABI-H ( $\mathrm{p}=0.089)$ and ABI-L $(p=0.88)$ was seen. But $A B I-M<1$ showed significant association with BZI $(p=0.022)$. A receiver operating characteristic (ROC) curve was drawn to know the value of low ABI-M in the diagnosis of BZI over CATI. We found that ABI-M of $<0.96$ was able to diagnose BZI (sensitivity $56.2 \%$, specificity $63.8 \%$, p $<0.05$ ) over CATI. (Figure 2).

Although the highest abnormality was detected in ABI-L, but compared to the CATI, the risk of having BZI was associated only with low ABI-M ( $p=0.022)$. To understand this phenomenon we looked into systolic BP of individual patients grouped under above mentioned three ABI sub-groups and calculated the mean SBP at right arm for each group. Results showed that compared to the other two ABI groups the difference in the mean SBP of low $(<1)$ and high $(\geq 1)$ ABI-M group was significant $(p=0.05$, Table-3).

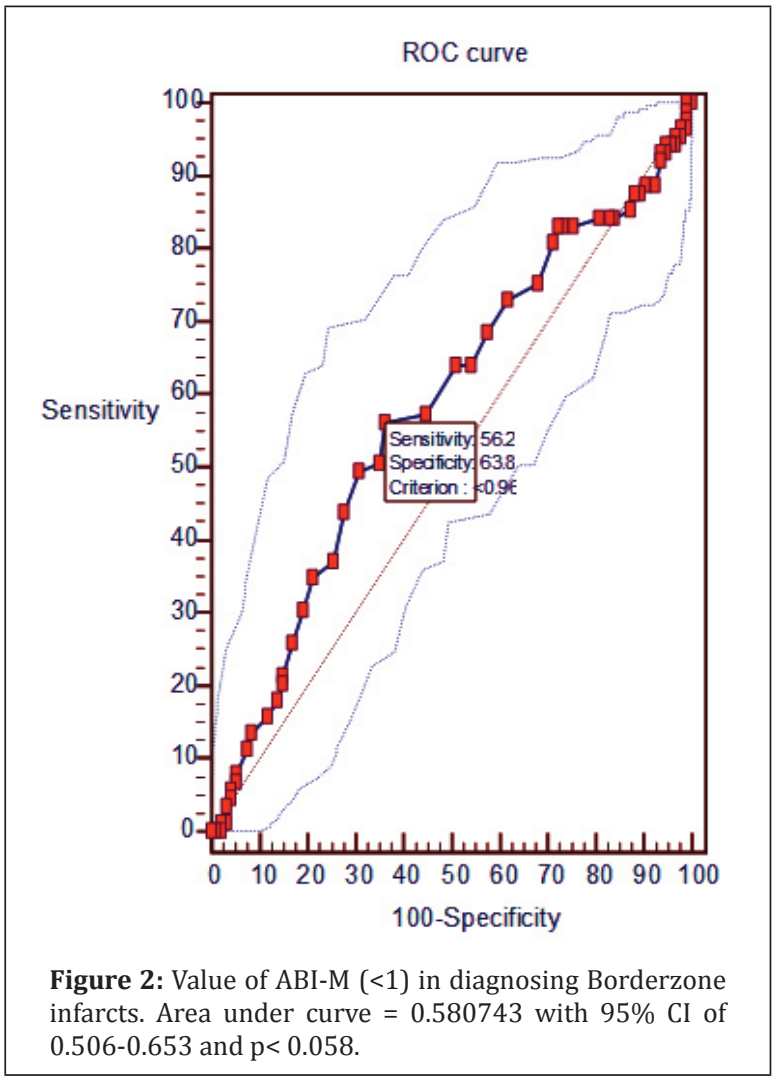

Multivariate binary logistic regression was performed to identify the significant predictor for BZI at $95 \%$ CI. The Table 4 summarizes the binary logistic regression model. Out of the incorporated risk factors only HTN $(\mathrm{p}<0.001)$ and ABI-M $(\mathrm{p}<0.033)$ are found to be the most significant predictor of BZI, the probability of the correct prediction being $67.2 \%$ (sensitivity $67.4 \%$ and specificity $67 \%$ ). The presence of dyslipidemia and the male gender had weak predictive value for BZI $(p<0.06)$.

\section{Discussion}

The presence of a severe degree of ICAS and hypoperfusion has been implicated in the etiopathogenesis of the BZI [8-10, 25]. Patients with cerebral vascular stenosis with poor collateral circulation when exposed to aggressive BP management, the presence of ICAS predisposes them to BZI and RS. Further, increasing BP improves the prognosis of BZI patients [26, 27]. Therefore, knowledge of ICAS seems essential to prevent and manage BZI [2]. The diagnosis of ICAS is possible with sophisticated medical gadgets but they are not of much use as a screening tool because of the high cost and poor availability. 
Table 2: Interlimb blood pressure difference vs. Borderzone infarcts.

\begin{tabular}{|c|c|c|c|c|c|}
\hline & Variable & $\begin{array}{c}\text { Borderzone infarcts } \\
(B Z I) \\
(n=89)\end{array}$ & $\begin{array}{c}\text { Core Arterial } \\
\text { Territory Infarcts } \\
\text { (CATI) } \\
(n=94)\end{array}$ & $\begin{array}{c}\text { OR } \\
(95 \% C I)^{\wedge}\end{array}$ & $\begin{array}{l}p \text {-value } \\
(\text { LOS })^{\pi}\end{array}$ \\
\hline \multirow{2}{*}{ ABI- $\mathrm{H}$} & $\begin{array}{l}<1.0 \\
(92)\end{array}$ & $\begin{array}{l}39 \\
(42.95)\end{array}$ & $\begin{array}{l}53 \\
(57.60)\end{array}$ & \multirow{2}{*}{$\begin{array}{l}0.772 \\
(0.33 \text { to } 1.08)^{\text {ns }}\end{array}$} & \multirow{2}{*}{$0.089^{\mathrm{ps}}$} \\
\hline & $\begin{array}{l}\geq 1.0 \\
(91)\end{array}$ & $\begin{array}{l}50 \\
(53.84)\end{array}$ & $\begin{array}{l}41 \\
(46.16)\end{array}$ & & \\
\hline \multirow{2}{*}{ ABI-M } & $\begin{array}{l}<1.0 \\
(118)\end{array}$ & $\begin{array}{l}50 \\
(42.38)\end{array}$ & $\begin{array}{l}68 \\
(57.62)\end{array}$ & \multirow{2}{*}{$\begin{array}{l}0.49 \\
(0.26-0.90)^{\mathrm{ns}}\end{array}$} & \multirow{2}{*}{$0.022^{\mathrm{s}}$} \\
\hline & $\begin{array}{l}\geq 1.0 \\
(65)\end{array}$ & $\begin{array}{l}39 \\
(60.00)\end{array}$ & $\begin{array}{l}26 \\
(40.00)\end{array}$ & & \\
\hline \multirow{2}{*}{ ABI- L } & $\begin{array}{l}<1 \\
(148)\end{array}$ & $\begin{array}{l}69 \\
(46.62)\end{array}$ & $\begin{array}{l}79 \\
(53.38)\end{array}$ & \multirow{2}{*}{$\begin{array}{l}0.65 \\
(0.52-1.66)^{\mathrm{ns}}\end{array}$} & \multirow{2}{*}{$0.88^{\mathrm{ns}}$} \\
\hline & $\begin{array}{l}\geq 1 \\
(35)\end{array}$ & $\begin{array}{l}20 \\
(57.14)\end{array}$ & $\begin{array}{l}15 \\
(42.86)\end{array}$ & & \\
\hline \multirow{2}{*}{ IASBD } & $\begin{array}{l}\geq 10 \\
(53)\end{array}$ & $\begin{array}{l}20 \\
(37.73)\end{array}$ & $\begin{array}{l}33 \\
(62.26)\end{array}$ & \multirow{2}{*}{$\begin{array}{l}0.53 \\
(0.27-1.03)^{\mathrm{ns}}\end{array}$} & \multirow{2}{*}{$0.060^{\mathrm{ps}}$} \\
\hline & $\begin{array}{l}<10 \\
(130)\end{array}$ & $\begin{array}{l}69 \\
(53.07)\end{array}$ & $\begin{array}{l}61 \\
(46.92)\end{array}$ & & \\
\hline \multirow{2}{*}{ IADBD } & $\begin{array}{l}\geq 10 \\
(46)\end{array}$ & $\begin{array}{l}22 \\
(47.82)\end{array}$ & $\begin{array}{l}24 \\
(52.18)\end{array}$ & \multirow{2}{*}{$\begin{array}{l}0.958 \\
(0.49-1.86)^{\mathrm{ns}}\end{array}$} & \multirow{2}{*}{$0.89^{\text {ns }}$} \\
\hline & $\begin{array}{l}<10 \\
(137)\end{array}$ & $\begin{array}{l}67 \\
(48.90)\end{array}$ & $\begin{array}{l}70 \\
(51.10)\end{array}$ & & \\
\hline
\end{tabular}

${ }^{\wedge}$ calculated as per Altman, 1991, ${ }^{\Uparrow}$ Pearson Chi-Square test, ABI-Ankle brachial index , OR-odds ratio, CI-confidence interval, LOSLevel of significance, IASBD- Interarm systolic blood pressure difference, IADBD- Interarm diastolic blood pressure difference, s-significant, ns-non significant.

Table 3: ABI and mean systolic blood pressure at right arm.

\begin{tabular}{|cccc|}
\hline \multirow{2}{*}{ ABI ratio } & \multicolumn{3}{c|}{ Systolic BP mmHg mean $\pm S D$} \\
\cline { 2 - 4 } & $A B I-H$ & $A B I-M$ & $A B I-L$ \\
\hline$<1$ & $144.98 \pm 24.9$ & $144 \pm 23.5$ & $142.35 \pm 23.51$ \\
$>=1$ & $138.71 \pm 21.56$ & $137 \pm 22.88$ & $139.8 \pm 23.43$ \\
$\begin{array}{c}\text { p- value } \\
\text { (LOS) }\end{array}$ & $0.70^{\mathrm{ns}}$ & $0.05^{\mathrm{s}}$ & $0.56^{\mathrm{ns}}$ \\
\hline
\end{tabular}

*Comparison of means, ns=nonsignificant, $\mathrm{s}=$ significant, LOSLevel of significance, ABI-Ankle brachial index.

A strong association of PAD with ICAS and its easy identification by measuring the IABD and ABI is well established $[13,15]$. In most of the previous research, patients have been recruited retrospectively to study BZI either to identify the stroke mechanisms or cerebral vascular abnormalities or MRI characteristics of the BZI.
Through our single-blind study, we have attempted to identify predictors of BZI and explore the association of MRI discernible BZI and inter-arm BP difference in consecutive acute stroke patients by deploying IASBD, IADBD and ABI measurements as tools. To best of our knowledge, no such work has been done in the past.

Since our study design and patient population differ from the earlier works so do our demographic findings. For example, we recruited subjects consecutively and found BZI in $48.63 \%$ of them. Young et al. attempted to study the mechanism of IBZ and EBZ infarcts in MCA territory by retrospectively recruiting the stroke patients based upon vascular studies. They found BZI in only $12.7 \%$ of their patients [25]. In contrast to them, Bogousslavsky et al., recruited consecutive patients with acute stroke and found BZI in $53 \%$ of their subjects [28]. 
Table 4: Multivariate binary logistic regression analysis of cerebrovascular risk factors for botrderzone infarcts.

\begin{tabular}{|c|c|c|c|c|c|c|}
\hline \multirow{2}{*}{ Predictors } & \multirow{2}{*}{$\beta$} & \multirow{2}{*}{ Std. Error } & \multirow{2}{*}{$\begin{array}{c}p \text {-value } \\
\text { (LOS) }\end{array}$} & \multirow{2}{*}{ Odds ratio } & \multicolumn{2}{|c|}{$95 \% C I$} \\
\hline & & & & & Upper & Lower \\
\hline Age (Year) & -0.012 & 0.013 & $\mathrm{p}>0.05^{\mathrm{ns}}$ & 0.99 & 0.96 & 1.01 \\
\hline Sex (Male) & 0.676 & 0.448 & $\mathrm{p}<0.06^{\mathrm{ps}}$ & 1.97 & 0.82 & 4.73 \\
\hline Hypertension & 1.431 & 0.420 & $\mathrm{p}<0.001^{\mathrm{s}}$ & 4.18 & 1.84 & 9.53 \\
\hline DM (Present) & -0.353 & 0.355 & $\mathrm{p}>0.05^{\mathrm{ns}}$ & 0.70 & 0.35 & 1.41 \\
\hline Smoking $(\mathrm{Y})$ & 0.451 & 0.442 & $\mathrm{p}>0.05^{\mathrm{ns}}$ & 1.57 & 0.66 & 3.74 \\
\hline Alcohol (Y) & -0.031 & 0.486 & $\mathrm{p}>0.05^{\mathrm{ns}}$ & 0.97 & 0.37 & 2.51 \\
\hline Prior Stroke History (Y) & 1.184 & 0.784 & $\mathrm{p}>0.05^{\mathrm{ns}}$ & 3.27 & 0.70 & 15.19 \\
\hline Past IHD Hist. (Y) & 0.935 & 0.629 & $\mathrm{p}>0.05^{\mathrm{ns}}$ & 2.55 & 0.74 & 8.74 \\
\hline Dyslipidemia (Y) & 1.570 & 0.826 & $\mathrm{p}<0.06^{\mathrm{ns}}$ & 4.81 & 0.95 & 24.25 \\
\hline IASBP ( $\geq 10 \mathrm{mmHg}$ ) & -0.499 & 0.406 & $\mathrm{p}>0.05^{\mathrm{ns}}$ & 0.61 & 0.27 & 1.35 \\
\hline IADBP ( $\geq 10 \mathrm{mmHg}$ ) & 0.096 & 0.393 & $\mathrm{p}>0.05^{\mathrm{ns}}$ & 1.10 & 0.51 & 2.38 \\
\hline ABI-Mean $(<1.0)$ & -0.755 & 0.354 & $\mathrm{p}<0.033^{\mathrm{s}}$ & 0.47 & 0.24 & 0.94 \\
\hline
\end{tabular}

Y-Yes, N-No; LOS- Level of significance; CI- Confidence interval, Log odds of border zone infarcts $=-0.879-0.012 \times$ Age $($ year $)+$ $0.676 \times$ Sex ( 1 If male and 0 If female) $+1.431 \times$ Hypertension ( 1 If present and 0 If absent) $-0.353 \times$ Diabetes Mellitus ( 1 If present and 0 If absent) $+0.451 \times$ Smoking ( 1 If present and 0 If absent) $-0.031 \times$ Alcohol ( 1 If present and 0 If absent) $+1.184 \times$ History of Past Stroke (1 If present and 0 If absent) $+0.935 \times$ History of Ischemic Heart Disease (1 If present and 0 If absent) $+0.255 \times$ Dyslipidemia (1 If absent and 0 If present) $+1.570 \times$ Dyslipidemia (1 If present and 0 If absent) $-0.499 \times$ Inter-arm systolic blood pressure difference ( 1 If $\geq 10 \mathrm{mmHg}$ and 0 If $<10 \mathrm{mmHg}$ ) $+0.096 \times$ Inter-arm diastolic blood pressure difference (1 If $\geq 10 \mathrm{mmHg}$ and 0 If $<10 \mathrm{mmHg})+0.495 \times$ Inter-limb systolic blood pressure difference ( 1 If $\geq 10 \mathrm{mmHg}$ and 0 If $<10 \mathrm{mmHg})-0.090 \times$ Interlimb diastolic blood pressure difference ( 1 If $\geq 10 \mathrm{mmHg}$ and 0 If $<10 \mathrm{mmHg}$ ) $-0.755 \times$ ankle-brachial index average ( 1 If $<1.0$ and 0 If $\geq 1.0$ ).

The previous research on BZI can be divided into two broad groups: (a) those which recruited patients only of BZI and studied the mechanisms of IBZ and EBZ infarcts; (b) those which aimed to compare the CATI with BZI. Since the former type of studies made a comparison between the subgroups of BZI, hence did not find much significant difference in the demographic or clinical risk factor other than HTN $[11,24,28]$. In contrast to first the second type of studies has reported age, HTN, dyslipidemia, male gender, and T2DM to have higher odds for having BZI [30, 31]. We compared BZI with CATI and found that in addition to HTN, patients with male gender, dyslipidemia, IHD, prior stroke, and smoking have higher odds of having BZI.

Regarding inter-arm BP difference we have the following observations: (a) although the low ABI-M $(<1)$ is associated with BZI ( $p=0.033)$ but it predicts BZI over CATI with rather low sensitivity and specificity (56.2 and 63.8 respectively). Low $\mathrm{ABI}$ is known to be associated with CATI also [15]. Because we compared BZI with the CATI patients the predictive strength probably appears low; (b) High IADBP and IASBP have no association with BZI as compared with CATI. At first glance, this observation might appear to be anomalous but is not unexpected. IASBD and IADBD have a strong association with PAD but not with ICAS [32]. In contrast, ABI has a strong association with ICAS [33]. (c) The predictive value for BZI of ABI-M $(<1)$ is higher than ABI-H and ABI-L because the former incorporated the mean of SBP while later two take into consideration either the highest or the lower value of SBP. This observation is supported by the fact that the mean SBP in our patients with abnormal $(<1)$ ABI-M was significantly higher than that in persons with ABI-M value of $>1$. (Table 3). 
Our results suggest that low ABI-M, although not specific, is a sensitive method to identify persons at risk of BZI, particularly in the presence of HTN.

The collateral circulation is also a critical determinant of cerebral perfusion pressure in acute cerebral ischemia [34]. It is known that the development of BZI depends upon the status of the cerebral collateral circulation, which is known to be suboptimal in persons with BZI [2]. The development of collaterals is further impaired in presence of systemic HTN [35]. Catena et al. concluded that hypertension is a strong risk factor of atherosclerosis and carotid artery stenosis which in turn are risks of internal BZI [36]. Our results also suggest that ABI-M $(<1)$ with hypertension could be a surrogate marker of ICAS and therefore is associated with BZI.

\section{Conclusion}

Low ABI-M $(<1)$ could be a marker for the presence of ICAS in patients of ischemic stroke especially in patients with BZI. It is easy to calculate and could be used to identify patients at risk for BZI in the stroke population. Subset of stroke patients with HTN, if also have low ABI-M should be investigated further for presence of BZI and ICAS before aggressive BP control.

Our study has certain limitations arising due to the exclusion of a significant number of patients for want of the MRI. The predictive value of low $\mathrm{ABI}-\mathrm{M}$ should be further studied in a multicentric study incorporating different ethnic groups and the normal population as control.

Main points: (1) Ankle-brachial index (ABI) is easy to calculate and can be used to identify patients at risk for BZI in the stroke population. (2) Low ABIMean $(<1)$ can be a marker for the presence of ICAS in patients of ischemic stroke especially in patients with border zone infarcts (BZI). (3) Subset of stroke patients with HTN, if also have low ABI-Mean should be investigated further for presence of BZI and intracranial arterial stenosis before aggressive BP control.

\section{Acknowledgement}

The authors acknowledge Dr. Balkishan Sharma, Associate professor (Statistics), Department of Preventive and Social Medicine and Dr Nitisha
Goyal, Senior resident, Department of Neurology for contributions to this work.

\section{Conflicts of interest}

Authors declare no conflicts of interest.

\section{References}

[1] Kim JB, Kang GH, Kim HJ, Ahn SO, Kim NY, et al. Magnetic Resonance Imaging in Acute Ischemic Stroke Treatment. J Stroke. 2014; 16(3):131-145.

[2] Wabnitz AM, Derdeyn CP, Fiorella DJ, Lynn MJ, Cotsonis GA, et al. Hemodynamic markers in the anterior circulation as predictors of recurrent stroke in patients with intracranial stenosis. Stroke. 2019; 50(1):143-147.

[3] Zhao W, Wu J, Liu J, Wu Y, Ni J, et al. Trends in the incidence of recurrent stroke at 5 years after the first-ever stroke in rural China: A population-based stroke surveillance from 1992 to 2017. Aging (Albany NY). 2019; 11(6):1686-1694.

[4] Wabnitz AM, Derdeyn CP, Fiorella DJ, Lynn MJ, Cotsonis GA, et al. infarct patterns in the anterior circulation as predictors of recurrent stroke in the medical arm of SAMMPRIS. Stroke. 2016; 47:A103.

[5] Momjian-Mayor I, Baron JC. The pathophysiology of watershed infarction in internal carotid artery disease: review of cerebral perfusion studies. Stroke. 2005; 36(3):567-577.

[6] Mounier-Vehier F, Leys D, Godefroy O, Rondepierre P, Marchau M, et al. Borderzone infarct subtypes: preliminary study of the presumed mechanism. Eur Neurol. 1994; 34(1):11-15.

[7] Bladin CF, Chambers BR. Frequency and pathogenesis of hemodynamic stroke. Stroke. 1994; 25(11):2179-2182.

[8] Brierley JB, Excell BJ. The effects of profound systemic hypotension upon the brain of $\mathrm{m}$. rhesus: Physiological and pathological observations. Brain. 1966; 89(2):269-298.

[9] Dong MX, Hu L, Huang YJ, Xu XM, Liu Y, et al. Cerebrovascular risk factors for patients with cerebral watershed infarction: A case-control study based on computed tomography angiography in a population from Southwest China. Medicine (Baltimore). 2017; 96(28):e7505.

[10] Lee PH, Oh SH, Bang OY, Joo IS, Huh K. Isolated middle cerebral artery disease: clinical and neuroradiological features depending on the pathogenesis. J Neurol Neurosurg Psychiatry. 2004; 75(5):727-732.

[11] Vyas A, Saini TC, Kumawat BL, Sharma CB. Clinical, demographic and neuroradiological features of different types of cerebral border zone infarcts in North-west India. Indian J Med Spec. 2018; 9(4):195-199.

[12] Tummala R, Banerjee K, Mahajan K, Gupta A. Prevalence and Risk Factors of Peripheral Vascular Disease in Rural India: A cross Sectional Study Circulation. 2016; 134:A12714.

[13] ChangY,ChoiGS, LimSM,KimYJ,SongTJ.InterarmSystolic and Diastolic Blood Pressure Difference Is Diversely Associated With Cerebral Atherosclerosis in Noncardioembolic Stroke Patients. Am J Hypertens. 2018; 31(1):35-42.

[14] Miura T, Minamisawa M, Ueki Y, Abe N, Nishimura H, et al. Impressive predictive value of ankle-brachial index for very long-term outcomes in patients with cardiovascular disease: IMPACT-ABI study. PLoS One. 2017;12(6):e0177609. 
[15] Fan H, Hu X, Yu W, Cao H, Wang J, et al. Low ankle-brachial index and risk of stroke. Atherosclerosis. 2013; 229(2):317323.

[16] Pickering TG, Hall JE, Appel LJ, Falkner BE, Graves J, et al. recommendations for blood pressure measurement in humans and experimental animals. Circulation. 2005; 111(5):697-716

[17] Miname M, Bensenor IM, Lotufo PA. Different methods of calculating ankle-brachial index in mid-elderly men and women: the Brazilian longitudinal study of adult health (ELSA-Brasil). Braz J Med Biol Res. 2016; 49(12):e5734.

[18] Verberk WJ, Kollias A, Stergiou GS. Automated oscillometric determination of the ankle-brachial index: a systematic review and meta-analysis. Hypertension Research 2012; 35(9):883-891.

[19] Yamauchi H, Nishii R, Higashi T, Kagawa S, Fukuyama $\mathrm{H}$. Hemodynamic compromise as a cause of internal border-zone infarction and cortical neuronal damage in atherosclerotic middle cerebral artery disease. Stroke. 2009; 40(12):3730-3735.

[20] Mangla R, Kolar B, Almast J, Ekholm SE. Border zone infarcts: Pathophysiologic and imaging characteristics. Radio Graphics 2011; 31(5):1201-1214.

[21] Kim SA, Kim JY, Park JB. Significant interarm blood pressure difference predicts cardiovascular risk in hypertensive patients: CoCoNet study. Medicine (Baltimore). 2016; 95(24):e3888.

[22] Comparison of means calculator. Accessed on 2020 Jan 09. Available from: https://www.medcalc.org/calc/ comparison_of_means.php

[23] $t$ test calculator. Accessed on 2020 Jan 09. Available from: http://www.graphpad.com/quickcalcs/ttest1/

[24] Microsoft Excel. Accessed on 2017 Mar 10. Available from: https://products.office.com/enus/microsoft-excel-2010

[25] Yong SW, Bang OY, Lee PH, Li WY. Cortical border-zone infarction. Stroke. 2006; 37(3):841-846.

[26] Yu YP, Tan L. The vulnerability of vessels involved in the role of embolism and hypoperfusion in the mechanisms of ischemic cerebrovascular diseases. Biomed Res Int. 2016; 2016:8531958.

[27] Chalela JA, Dunn B, Todd JW, Warach S. Induced hypertension improves cerebral blood flow in acute ischemic stroke. Neurology. 2005; 64(11):1979.

[28] Bogousslavsky J, Regli F. Unilateral watershed cerebral infarcts. Neurology. 1986; 36(3):373-377.

[29] El-Gammal TM, Bahnasy WS, Ragab OAA, Al-Malt AM. Cerebral border zone infarction: an etiological study. Egypt J Neurol Psychiatr Neurosurg. 2018; 54(1):6.

[30] Mounier-Vehier F, Leys D, Godefroy O, Rondepierre P, Marchau M, et al. Borderzone infarct subtypes: Preliminary study of the presumed mechanism. Eur Neurol. 1994; 34:11-15.

[31] Hedera P, Bujdáková J, Traubner P, Pancák J. Stroke risk factors and development of collateral flow in carotid occlusive disease. Acta Neurol Scand. 1998; 98(3):182-186.

[32] Kim J, Song TJ, Song D, Oh HS, Kim JO, et al. Association of large inter-arm blood pressure difference with mortality and systemic atherosclerosis in acute stroke patients. Stroke. 2013; 44(4):AWP130.
[33] Barreto-Neto N, Barros AD, Jesus PA, Reis CC, Jesus ML, et al. Low ankle-brachial index is a simple physical exam sign predicting intracranial atherosclerotic stenosis in ischemic stroke patients. J Stroke Cerebrovasc Dis. 2016; 25(6):1417-1420.

[34] Caplan LR, Hennerici M. Impaired clearance of emboli (washout) is an important link between hypoperfusion, embolism, and ischemic stroke. Arch Neurol. 1998; 55(11):1475-1482.

[35] Hedera P, Bujdáková J, Traubner P, Pancák J. Stroke risk factors and development of collateral flow in carotid occlusive disease. Acta Neurol Scand. 1998; 98(3):182-186.

[36] Catena C, Colussi G, Url-Michitsch M, Nait F, Sechi LA. Subclinical carotid artery disease and plasma homocysteine levels in patients with hypertension. J Am Soc Hypertens. 2015; 9(3):167-175. 